\title{
INTERESSE E ATITUDES DOS ESTUDANTES DE ADMINISTRAÇÃO EM RELAÇÃO À ÁREA CONTÁBIL
}

\section{INTEREST AND ATTITUDES OF STUDENTS IN ADMINISTRATION REGARDING THE ACCOUNTING AREA}

\section{INTERÉS Y ACTITUDES DE LOS ESTUDIANTES DE ADMINISTRACIÓN EN RELACIÓN AL ÁREA CONTABLE}

\section{FRANCISCO JOSÉ DA COSTA}

Possui graduação em Administração de empresas pela Universidade Estadual do Ceará (2000), mestrado em Administração pela mesma instituição (2003) e doutorado em Administração de Empresas pela Fundação Getulio Vargas - SP (2007)

franzecosta@gmail.com

\section{THIAGO ALVES PAIVA}

Mestrando (2008.1 - 2009.2) do Curso de Mestrado Acadêmico em Administração (CMAAd) da Universidade Estadual do Ceará (UECE) e Bacharel em Administração de Empresas por esta instituição em 2005.2

talvesp@gmail.com

\section{JACQUELINE DOS ANJOS DA ROCHA}

Mestre em Administração na Universidade Estadual do Ceará. Graduada em Administração de Empresas pela Universidade Estadual do Ceará (2007)

jackdanjos@yahoo.com.br

\section{ROBERTO RODRIGUES RAMOS}

Possui graduação em Administração pela Universidade Estadual do Ceará (2001) e mestrado pela mesma instituição (2009). Atualmente é professor efetivo do Curso de Administração da Universidade Federal do Ceará - Campus Cariri robertoramos@cariri.ufc.br 


\section{repec}

Francisco José da Costa, Thiago Alves Paiva, Jacqueline dos Anjos da Rocha e Roberto Rodrigues Ramos

\section{RESUMO}

Este estudo tem por objetivo analisar o nível de interesse e as atitudes de estudantes de Administração em relação às disciplinas da área contábil presente no curso. Inicialmente, apresentaram-se no referencial teórico os elementos gerais da Contabilidade, com seus conceitos, objetivos e principais áreas de estudo; em seguida, discutiram-se sobre as disciplinas da área contábil mais presentes nos cursos de Administração e sua importância para a tomada de decisões organizacionais; por fim, apresentam-se os tópicos centrais da pesquisa, tais como percepção de habilidade, domínio do conteúdo, importância, dificuldade e autoconfiança. Após a fase de revisão da literatura, foi realizado estudo de campo com dados coletados de 157 estudantes de três instituições de ensino superior da cidade de Fortaleza. Os dados foram avaliados por meio de análise descritiva, análise de regressão e ainda análise de cluster. Verificou-se principalmente: (1) que os estudantes apresentam um interesse apenas moderado pela área e, quanto às atitudes, estes atribuíram uma importância elevada para a área; (2) que o interesse do estudante é influenciado pela sua autoconfiança e pela importância percebida, não havendo influência significativa de segurança quanto ao domínio de habilidades ou dificuldade percebida; (3) a existência de três grupos, um dos quais se mostrou muito entusiasmado com a área (22,3\%), outro mostrou tendência moderada $(44,6 \%)$ e o último grupo mostrou-se bastante avesso à área contábil $(33,1 \%$ do total).

Palavras-chave: Cursos de Administração; Formação em Administração; Ciências Contábeis.

\section{ABSTRACT}

This study aims to examine the interest level and attitudes of business administration students in relation to the accounting disciplines present in the course. Initially, a theoretical discussion was carried out, with the presentation of general accounting elements, concepts, objectives and main areas of study; also discussed were the accounting disciplines present in the business administration courses and their importance for decision making; and finally, the main topics of the study were presented. After the stage of literature review, a field study was conducted with data collected from 157 students from three higher education institutions in the city of Fortaleza. The data was analyzed using descriptive analysis techniques, regression analysis and cluster analysis. The main results were that: (1) students have only a moderate interest in the accounting area, and, regarding their attitudes, they attached a high importance to the area; (2) it was evidenced that the students interest in the area is influenced by their self-confidence and the perceived importance, but there is no significant influence produced by mastery of abilities or perceived difficulty; (3) three groups could be delineated, one with very excited students about the area $(22.3 \%)$, 
another with a moderate interest and attitude (44.6\%), and the last group very averse to the accounting area (33.1\% of total).

Key words: Management Courses; Management Education; Accounting.

\section{RESUMEN}

Este estudio tiene por objetivo analizar el nivel de interés y las actitudes de estudiantes de Administración en relación a las disciplinas del área contable presente en el curso. Inicialmente, presentó en el referencial teórico los elementos generales de la contabilidad, con sus conceptos, objetivos y principales áreas de estudio; en seguida discutió sobre las disciplinas del Área Contable más presentes en los cursos de Administración y su importancia para la tomada de decisiones organizacionales; por fin, se presentan los tópicos centrales de la pesquisa, tales como percepción de habilidad, dominio del contenido, importancia, dificultad y autoconfianza. Después de la fase de revisión de la literatura, fue realizado estudio de campo con datos colectados junto a 157 estudiantes de tres instituciones de enseñanza superior de la ciudad de Fortaleza. Los datos fueron evaluados a través de análisis descriptivo, análisis de regresión y también análisis de cluster. Fue verificado principalmente que: (1) los estudiantes presentan un interés sólo moderado por el área y, en lo referente a las actitudes, éstos atribuyeron una importancia elevada para el área; (2) el interés del estudiante es influenciado por su autoconfianza y por la importancia percibida, no habiendo influencia significativa de seguridad en lo referido al dominio de habilidades o dificultad percibida; (3) fue observada la existencia de tres grupos, uno de los cuales se mostró muy entusiasmado con el área (22,3\%), otro mostró tendencia moderada (44,6\%), y el último grupo se mostró bastante adverso al área contable (33,1\% del total).

Palabras clave: Cursos de Administración; Formación en Administración; Ciencias Contables.

\section{INTRODUÇÃO}

A formação do profissional em nível superior é um dos desafios centrais para a categoria profissional dos administradores, especialmente em razão da necessidade de uma legitimidade como profissão e a integração de uma formação sistemática com foco teórico e prático. Essas demandas refletem diretamente na estruturação dos cursos de Administração e não são apenas indicações genéricas. Antes, servem de norte para o desenvolvimento das diversas atividades de formação, em especial nos cursos de bacharelado. Isso parece bem evidente no que anunciam as Diretrizes Curriculares Nacionais de Graduação em Administração (cf. ANDRADE; AMBONI, 2004; MEC, 2005) ou nos projetos pedagógicos de cursos de várias instituições de ensino superior. 
Pensando especialmente nesses cursos (Bacharelado em Administração), observase que são normalmente divididos em áreas específicas, como, por exemplo: administração de recursos humanos, marketing, administração da produção, logística, gestão financeira e orçamentária, entre outras. Adicionalmente, e com a finalidade de desenvolver os conhecimentos e habilidades necessários para que os administradores atuem com mais segurança e profissionalismo, os cursos de Administração trazem em suas grades curriculares disciplinas de áreas do conhecimento complementares, tais como Psicologia, Ciências Econômicas, Tecnologia da Informação, Métodos Quantitativos, Ciências Contábeis, entre outras.

Neste trabalho, optou-se por dar uma ênfase maior às Ciências Contábeis, destacada como área de formação complementar e que apresenta uma série de ferramentas necessárias ao desempenho da atividade gerencial, principalmente, no campo da gestão financeira e orçamentária. Apresenta-se como problema a seguinte questão: Qual o nível de interesse e as atitudes dos estudantes de Administração em relação à àrea contábil? Nessa perspectiva, o presente estudo tem por objetivo geral analisar o nível de interesse dos estudantes de Administração pelas disciplinas da área contábil integrantes da grade curricular do curso. De modo complementar, pretendem-se analisar outros aspectos associados ao interesse do estudante, destacando-se aqui tópicos como: percepção de domínio de habilidades nos conhecimentos contábeis; percepção de importância da área contábil nos cursos de Administração; percepção de dificuldade dos conteúdos das Ciências Contábeis; e nível de autoconfiança.

O restante do artigo traz mais quatro tópicos: o seguinte faz uma revisão de literatura, com ênfase na conceituação e direcionamento da pesquisa em cada uma das dimensões de análise selecionadas; logo após, é descrita a metodologia utilizada na pesquisa de campo; posteriormente, apresenta-se a análise dos resultados e, ao final, são feitas as considerações finais, contendo as implicações da pesquisa, suas limitações e sugestões para futuros trabalhos no tema.

\section{REFERENCIAL TEÓRICO}

Neste item, são apresentados o referencial teórico do estudo, com um debate preliminar sobre a Contabilidade e sua importância para os cursos de Administração e, em seguida, a exposição dos tópicos específicos da pesquisa.

\subsection{Elementos gerais da Contabilidade}

A Contabilidade pode ser tratada sob dois aspectos: como teoria e como prática. Sob o ponto de vista teórico, a Contabilidade "estabelece princípios e regras de conduta a serem seguidas pelos profissionais da área contábil, com o objetivo de aprimorar e uniformizar os procedimentos por eles adotados". Já em uma perspectiva prática, "envolve o uso de téc- 
nicas ou procedimentos por meio dos quais a Contabilidade teórica e seus princípios são postos em prática" (FERREIRA, 2007, p. 1-2).

Segundo propõem ludícibus e Marion (2000), as Ciências Contábeis estão associadas a todas as atividades humanas, dado que, em quase tudo, se operacionalizam contagens. Segundo o autor, foi a necessidade de acompanhar a evolução dos patrimônios que deu motivo ao nascimento e ao desenvolvimento dessa ciência como área profissional e acadêmica.

Franco (1997) propõe uma definição geral da Contabilidade como a Ciência que estuda o patrimônio de uma entidade e suas variações. Assim, a Ciência Contábil estuda os fenômenos e os fatos que ocorrem com a riqueza do homem e os classifica (bens, direitos e obrigações) em aspectos quantitativos que compõem o patrimônio, tais como: dinheiro, mercadorias, móveis, máquinas, instalações, contas a receber ou a pagar. Nas palavras de Franco (1997, p. 19), tem-se:

[...] seu campo de aplicação é o das entidades econômico-administrativas, assim chamadas aquelas que, para atingirem seu objetivo, seja ele econômico ou social, utilizam bens patrimoniais e necessitam de um órgão administrativo que pratica os atos de natureza econômica e financeira necessárias a seus fins.

Conforme apontam Hendriksen e Van Breda (1999, p.104-105), "o objetivo da Contabilidade é fornecer um conjunto de relatórios financeiros para usuários determinados com relação à riqueza ou relações econômicas da empresa".

Nesse contexto, Marion (2009) acrescenta que a Contabilidade é responsável por coletar os dados econômicos, mensurá-los monetariamente, registrá-los e sumarizá-los em relatórios ou comunicados que sejam de fácil entendimento para os gestores e dirigentes que planejam e controlam as organizações.

De forma mais detalhada, Sá (1998, p. 89) propõe que as finalidades da Contabilidade são: (i) fornecer orientação para investidores e para o mercado de capitais; (ii) fornecer orientações sociais e trabalhistas; (iii) contribuir para análises científicas de modelos de comportamento da riqueza para ensejar decisões administrativas; (iv) auxiliar na construção de modelos para a prosperidade; (v) auxiliar nos controles governamentais de fiscalização e auditoria fiscal; (vi) servir como instrumento de provas judiciais e perícia contábil; (vii) contribuir para revisões de ocorrências e efeitos orçamentários; (viii) fornecer explicação sobre atos patrimoniais e análises contábeis; e (ix) contribuir na investigação sobre a regularidade da gestão.

De forma complementar, a Comissão de Valores Mobiliários (CVM, 1986) entende que a Contabilidade, além de gerar informações, permite explicar os fenômenos patrimo- 
niais, construir modelos de prosperidade, efetuar análises, controlar, prever e projetar exercícios futuros. Em resumo, a área contábil deve fornecer informações aos dirigentes das organizações de modo que Ihes permitam acompanhar o desenvolvimento das atividades organizacionais e avaliar os resultados decorrentes dessas atividades, utilizando-se dos relatórios contábeis como instrumentos de apoio para traçar metas e políticas que contribuam para o alcance dos objetivos organizacionais.

$\mathrm{Na}$ prática, as áreas da Contabilidade estão interligadas dentro dos processos no ambiente organizacional, mas, didaticamente, as teorias contábeis estão divididas em diversos ramos ou áreas. Iudícibus (2009) destaca a Contabilidade pública e a Contabilidade privada como principais segmentos; entretanto, um detalhamento maior pode ser visualizado na Figura 1, conforme proposição de Ferreira (2007).

Figura 1 - Áreas ou ramos da Contabilidade.

Ciências Contábeis $\left\{\begin{array}{l|}\text { - Contabilidade Geral } \\ \text { - Contabilidade de Custos } \\ \text { - Contabilidade Bancária } \\ \text { - Contabilidade Pública } \\ \text { - Contabilidade de Seguros } \\ \text { - Análise de Demonstrações } \\ \text { - Auditoria }\end{array}\right.$

Fonte: Adaptado de Ferreira (2007, p. 3).

Conforme os conceitos descritos, na explanação das áreas de interesse e objetivos expostos, é possível perceber a relevância que o conhecimento de Contabilidade tem para profissionais de várias áreas de atuação no universo dos negócios. Por esta razão, alguns tópicos de Contabilidade são estudados em cursos distintos da graduação (Economia, Atuária, Direito...). Para esse trabalho, interessam especialmente os estudos desenvolvidos no âmbito dos cursos de graduação em Administração.

\subsection{Contabilidade em cursos de Administração}

Todos os cursos de Bacharelado em Administração possuem disciplinas contábeis, as quais são ensinadas aos futuros profissionais devido à forte presença da Contabilidade nas atividades organizacionais, em especial na área financeira. Conforme anunciam ludícibus e Marion (2009), é necessário que o profissional de Administração conheça e saiba interpretar os relatórios contábeis, tais como o balanço patrimonial, a demonstração de lucros e prejuízos acumulados, a demonstração do resultado do exercício, a demonstração 
dos fluxos de caixa e a Demonstração do Valor Adicionado (DVA). Adicionalmente, é necessário que ele tenha habilidades para fazer análises contábeis, reconhecer os custos e as respectivas formas de custeio, além de ter ciência do processo contábil.

Conforme observações exploratórias sobre currículos de cursos de Administração, em geral, iniciam os estudos na área de Contabilidade até o terceiro semestre do curso. As disciplinas mais estudadas são Contabilidade Geral e Contabilidade de Custos, seguidas de Análise de Balanços e, de forma menos presente, Contabilidade Tributária.

Contabilidade Geral é comumente uma disciplina que introduz os conceitos contábeis nos cursos de Administração, contemplando como temas principais: Princípios Fundamentais da Contabilidade, variações do patrimônio, plano de contas, escrituração, balanço patrimonial e demonstração de resultados. O objetivo é apresentar a Contabilidade como instrumento de planejamento e controle do fluxo de recursos dentro do patrimônio da empresa (IUDÍCIBUS; MARION, 2000).

Após os conceitos introdutórios de Contabilidade, normalmente é ofertada a disciplina de Contabilidade de Custos (também denominada Custo Empresarial), que abrange tópicos relacionados com tipos de custos, sistemas e métodos de custeio, procedimentos de formação de preço, orçamentos e relatórios empresariais (MARTINS, 2003).

A disciplina Análise de Balanços pode ser entendida como um misto do programa de Administração financeira e de Contabilidade, por tratar de tópicos como: estrutura dos balanços, análise da estrutura financeira da empresa, análise de circulação de bens e valores e análise da produtividade de capitais, entre outros. As análises normalmente são efetuadas a partir de indicadores financeiros extraídos dos diversos demonstrativos (MATARAZZO, 2003).

Por fim, encontra-se a disciplina de Contabilidade Tributária, que, em geral, é proposta como disciplina eletiva. A relevância dessa disciplina é evidente quando se sabe que o Brasil possui mais de 60 tributos, entre impostos, taxas e contribuições. Cabe, portanto, ao profissional de Administração conhecer e dominar as diversas formas de planejamento e redução de custos com tributos, bem como buscar novas formas legais para reduzir o pagamento dos tributos inerentes às diversas atividades empresariais (NAZARIO; MENDES; AQUINO, 2006).

O valor dos conhecimentos contábeis em Administração é evidente quando se verifica a forte articulação que guarda com as disciplinas do núcleo profissional, de modo especial com as disciplinas Administração Financeira e Orçamentária, mas também com a área de recursos humanos (concernente a contas de salário, benefícios, etc.) e de produção (na análise de custos), fornecendo conceitos e ferramentas básicos que propiciam ao estudante desenvolver a capacidade de análise de relatórios com resultados operacionais da empresa e tomar decisões típicas de quem trabalha na área financeira e/ou dirige organizações. 
Merece destaque ainda o desenvolvimento da área conhecida como Controladoria, responsável por assegurar a disponibilidade de informações para que haja qualidade no processo decisório do gestor (MENDES, 2002). Essa área faz convergir de maneira mais intensa os conhecimentos dos dois cursos (Administração e Contabilidade) e parece seguir para se consolidar como uma área multidisciplinar.

Pouco estudada nos cursos de Administração, porém de grande importância para a tomada de decisões dos gestores nas organizações, está a Contabilidade Gerencial. Este conceito refere-se às práticas utilizadas pela Contabilidade nas empresas e que contribuem para a condução dos negócios por meio de sua finalidade informativa, tais como: métodos de custeio, análise das relações custo-volume-lucro, método de predeterminação de custos, elaboração e uso de planos orçamentários e utilização de medidas de retorno.

De acordo com Souza, Lisboa e Rocha (2003), este ramo da Contabilidade vem ganhando reconhecimento e espaço devido a sua importância no processo de tomada de decisão. Os autores alertam, no entanto, que, para atingir seus objetivos adequadamente, é preciso adotar práticas condizentes com o atual ambiente competitivo no qual as organizacionais se encontram.

Corroborando com o entendimento de que a Contabilidade precisa prover os gestores de informações úteis e que atendam aos aspectos legais das organizações, Paulo (2002) identifica uma lista de características ou qualidades que as informações contábeis devem conter, tais como: entendimento e conhecimento anterior por parte dos tomadores de decisão, ou seja, compreensibilidade; oportunidade, significando que as informações devem chegar a tempo e proteger a empresa; confiabilidade; comparabilidade e relevância.

A seguir, são discutidos os tópicos centrais da pesquisa relacionados ao interesse e às atitudes dos estudantes de Administração em relação à área contábil.

\subsection{Tópicos da pesquisa}

O tópico central de análise deste artigo é o interesse pessoal do estudante de Administração pela área contábil. Apreciações sobre interesse têm sido recorrentemente procedidas em estudos sobre as áreas de formação em negócios, de modo mais enfático nas análises de interesse disciplinar. Exemplos ilustrativos são os estudos de Camey e Williams (2004), cuja análise focou o interesse pessoal de estudantes de negócios pela área de Marketing, e de Costa, Andrade e Lima (2008), que analisaram o interesse dos estudantes de Administração pela área de Produção e Operações.

Costa et al. (2008) desenvolveram uma análise do interesse de estudantes de Administração por uma área de conhecimentos complementares, com a qual produziram um escala de medição de atitudes quanto à área de métodos quantitativos. Seguindo nesta mesma perspectiva, para este artigo optou-se por analisar o interesse juntamente aos quatro aspectos associados a atitudes: segurança quanto ao domínio de habilidades da 
área contábil; percepção de dificuldades das disciplinas contábeis; percepção de autoconfiança e percepção de importância da área para o curso. A seguir são detalhados cada um desses tópicos.

- Segurança quanto ao domínio de habilidades: Costa et al. (2008) tomaram como conceito de habilidade o "grau de conhecimento efetivo dos estudantes sobre determinada demanda em termos de conhecimentos e aplicações". Conforme exposto no referencial teórico (subitem 2.2.), é evidente a conexão entre a área contábil e a Administração, o que não deixa dúvidas da importância do domínio de habilidades da área contábil pelo futuro profissional de Administração. Nesses termos, entendeu-se como relevante analisar o nível de segurança dos estudantes de Administração em relação aos conceitos básicos e técnicas contábeis.

- Percepção de importância da área para o curso: também foi analisada a percepção de relevância da área contábil nos cursos de Administração, tomando por base a análise da percepção das consequências profissionais e educacionais do conteúdo estudado nas disciplinas da área contábil, assim como a percepção de necessidade da área no curso (sobre este último aspecto, existe a obrigatoriedade legal de algumas disciplinas nos cursos; resta saber, por outro lado, o posicionamento dos estudantes).

- Percepção de dificuldade das disciplinas contábeis: além da análise da segurança quanto ao domínio de habilidades e da importância da área, também foi verificado se os estudantes de Administração consideram o estudo da área como complexo, ou seja, pretendeu-se analisar quão difícil os estudantes consideram os conteúdos das disciplinas contábeis estudadas nos cursos de Administração.

- Percepção de autoconfiança: o quarto aspecto analisado foi o da autoconfiança, que pode ser entendida como a crença pessoal que um indivíduo possui em seu sucesso no aprendizado e na consequente aplicação de um conjunto de conhecimentos adquiridos. A suposição geral é de que a autoconfiança pode possibilitar ao sujeito uma maior motivação, concentração e dedicação à tarefa a que se propõe.

Tomando por base alguns estudos com objetivos semelhantes ao deste artigo (COSTA; SOARES, 2008; COSTA; ANDRADE; LIMA, 2008), optou-se por analisar exploratoriamente a potencial influência dessas dimensões sobre o interesse dos estudantes de Administração pela área contábil. A suposição é de que há uma influência consistente desses aspectos no interesse, havendo um impacto positivo do domínio de habilidades, da 


\section{repec}

Francisco José da Costa, Thiago Alves Paiva, Jacqueline dos Anjos da Rocha e Roberto Rodrigues Ramos

autoconfiança e da percepção de importância; porém, a percepção de dificuldades impacta negativamente sobre o interesse dos estudantes pela área contábil.

\section{METODOLOGIA}

Esta pesquisa se iniciou com procedimentos exploratórios e discussão entre os autores com a finalidade de definir os aspectos relevantes para análise. Em um segundo momento, foi avaliada a adequação do referencial adotado e da proposta de escala disponível. Ao final, foram definidas as cinco dimensões de análise, a primeira associada ao interesse e as outras quatro inspiradas no conceito de atitude do estudante, conforme a proposição de Costa et al. (2008) comentada no item 2.3 acima.

Para a verificação, decidiu-se por uma abordagem dos estudantes por meio do questionário do tipo estruturado e não disfarçado. Na composição deste instrumento, foram inicialmente selecionadas questões categóricas associadas a informações sobre a condição do aluno no curso, sobre suas intenções futuras, sua experiência profissional, como também suas informações sociodemográficas.

Já nas questões associadas aos tópicos temáticos do estudo, foram extraídos itens da literatura disponível com as seguintes decisões: na avaliação de interesse, foram adaptados os itens do estudo de Costa e Soares (2008); na avaliação das atitudes, foram utilizados os itens da escala de Costa et al. (2008) para os construtos autoconfiança, importância percebida e dificuldade percebida; para o construto domínio de habilidades, foram extraídos oito itens da literatura especializada em Contabilidade (cf. itens 2.1 e 2.2). Todos os itens foram apresentados como afirmações, averiguando o grau de concordância por meio de escala Likert de 7 pontos ( 1 para discordo totalmente e 7 para concordo totalmente).

Logo após a elaboração do questionário, foi feita a coleta dos dados, tendo como universo os estudantes dos cursos de Administração de instituições públicas e privadas localizadas em Fortaleza, por meio de uma amostragem por conveniência e acessibilidade, com 157 estudantes abordados diretamente em três instituições. A aplicação foi realizada nos meses de outubro e novembro de 2008 e foi feita diretamente em sala de aula, com o apoio dos professores.

As informações correspondentes às características socioeconômicas e demográficas dos estudantes pesquisados estão expostas na Tabela 1. Destaca-se o fato de que $77 \%$ dos respondentes são solteiros, em sua maioria com idade acima de 24 anos (42,2\%) e igualmente divididos por gênero. 
Tabela 1 - Informações sociodemográficas (valores em percentual)

\begin{tabular}{|ll|lc|}
\hline \multicolumn{2}{|c|}{ Gênero } & \multicolumn{2}{c|}{ Estado civil } \\
\hline Masculino & & \multicolumn{1}{c|}{} \\
Feminino & 50,1 & Solteiro & 77,0 \\
& 49,9 & Casado & 18,2 \\
& & Outro & 4,7 \\
\hline \multicolumn{2}{|c|}{ Qual sua idade } & & \multicolumn{1}{c|}{ Renda familiar } \\
\hline Até 20 anos & 11,0 & Até $\mathrm{R} \$ 1.000,00$ & 26,6 \\
De 21 a 22 anos & 24,7 & De $\mathrm{R} \$ 1.001,00$ a $\mathrm{R} \$ 2.000,00$ & 30,9 \\
De 23 a 24 anos & 22,1 & De $\mathrm{R} \$ 2.001,00$ a $\mathrm{R} \$ 3.000,00$ & 18,7 \\
Acima de 24 anos & 42,2 & Acima de $\mathrm{R} \$ 3.000,00$ & 23,7 \\
\hline
\end{tabular}

Fonte: Dados da pesquisa (2008).

Após a coleta, os dados foram consolidados na planilha do software SPSS (versão 15). Em um primeiro momento, foram feitos os procedimentos exploratórios de análise de dados perdidos e de valores extremos. Tais procedimentos não indicaram a necessidade de maiores adaptações ou exclusão de entradas de dados ou variáveis. Em seguida, procedeu-se à extração das medidas, à descrição e à análise de resultados.

Os procedimentos de análise estatística foram de quatro tipos: análise exploratória da estrutura fatorial; análise descritiva; análise de regressão; e análise de agrupamentos. Todos os procedimentos foram realizados com suporte na literatura especializada (MALHOTRA, 1999; HAIR et al., 2005). Os detalhes dos procedimentos e decisões tomadas nessas análises estão apontados em cada subitem de análise do item seguinte.

\section{APRESENTAÇÃO DOS RESULTADOS}

A apresentação dos resultados está dividida em cinco tópicos: o primeiro descreve a amostra pesquisada no estudo; o segundo detalha as análises dos construtos definidos no levantamento teórico; o terceiro apresenta a análise da regressão múltipla realizada para testar as proposições; o quarto descreve a análise de agrupamento realizada; e, ao final, são apresentados comentários adicionais sobre os principais resultados encontrados.

\subsection{Descrição da amostra}

A amostra foi constituída de 157 estudantes dos cursos de graduação em Administração que já haviam cursado pelo menos uma disciplina de Contabilidade. Do total de alunos pesquisados, 43,9\% foram provenientes de instituições públicas e $56,1 \%$ de instituições privadas. Tal fato demonstra um equilíbrio quanto à natureza das instituições dos respondentes, cuja consequência é a possibilidade de se obter maior consistência em 


\section{repec}

Francisco José da Costa, Thiago Alves Paiva, Jacqueline dos Anjos da Rocha e Roberto Rodrigues Ramos

comparações posteriores. Os dados coletados mostraram que a maioria dos respondentes $(55,4 \%)$ estava cursando a segunda metade do curso.

Os estudantes também responderam a questões sobre ocupação atual, trabalho e experiência na área de Contabilidade. Nesse aspecto, foram consideradas 155 respostas válidas e desse quantitativo, 31,2\% afirmaram trabalhar ou ter trabalhado em atividades associadas à área de Contabilidade, sendo que $28 \%$ associaram a atividades próprias do trabalho e outros $3,2 \%$ a projetos da faculdade (os demais não estavam envolvidos com trabalho na área contábil). Em relação à ocupação funcional, os resultados indicaram que $68,7 \%$ dos estudantes trabalhavam em tempo integral, 14,9\% em meio período e 16,4\% não estavam trabalhando na ocasião da pesquisa.

Sobre as intenções futuras em relação a trabalho ao terminarem o curso, mais da metade dos respondentes $(56,8 \%)$ informou pretender buscar um emprego ou continuar no que já se encontrava; 30,4\% pretendiam iniciar o próprio negócio; 1,9\% pretendia trabalhar em empresa da família; e 10,9\% informam não pretender trabalhar após o término do curso. Já em relação à continuidade dos estudos após o término do curso, 51,6\% dos estudantes pesquisados indicaram a intenção de fazer curso de especialização; $25,8 \%$ pretendiam cursar outra graduação; 15,5\% pretendiam fazer curso de Mestrado; e 7,1\% dos respondentes pretendiam parar de estudar.

\subsection{Descrição dos construtos}

Este item apresenta os resultados das variáveis e dos construtos centrais da pesquisa. Inicialmente, os dados obtidos na pesquisa de campo, para o conjunto de variáveis de cada um dos construtos, foram submetidos a uma Análise Fatorial Exploratória para reafirmar a estrutura fatorial prevista na escala de origem. Os resultados das variáveis tenderam a confirmar a organização prevista, porém, no conjunto de variáveis relacionados a 'domínio de habilidades', as oito variáveis utilizadas fizeram emergir dois fatores. A análise do sentido de cada conjunto de variáveis agregadas indicou que uma parte das variáveis se associava a habilidades em um nível mais teórico e as outras a um nível mais prático. Nesses termos, decidiu-se por analisar esse construto nessas duas dimensões.

Em seguida, as variáveis, por construto, foram avaliadas em sua confiabilidade, a partir da utilização do coeficiente Alpha de Cronbach, tendo-se encontrado valores sempre elevados, o que assegurou que as variáveis estavam consistentemente medindo o que se pretendia medir (mínimo de 0,799).

De posse desses resultados, foram extraídas as médias e os desvios-padrão do conjunto de variáveis, os quais estão expostos no Apêndice deste artigo. Adicionalmente e considerando os resultados da análise fatorial e da extração da confiabilidade, decidiu-se por agregar as variáveis, procedimento que viabiliza a extração de uma medida geral por construto (BAGOZZI; EDWARDS, 1998). Assim, foram somados os escores das variáveis 
de um mesmo construto, por respondente, e retirada a média (pelo número de variáveis), o que permitiu a manutenção da escala no intervalo originalmente usado (de 1 a 7 ).

Para as novas variáveis geradas, foi dado o nome do construto correspondente e foram extraídas também as médias e os desvios padrão. Os resultados desse procedimento, juntamente com o valor do coeficiente alpha de cada construto, estão expostos na Tabela 2. Para se ter uma ideia mais consistente do sentido desses resultados, e considerando que a escala foi de 7 pontos, foi adotado o seguinte critério: valores de média até 3,99 são considerados baixos; de 4,00 a 5,50 são intermediários; e acima de 5,50 são elevados; para os desvios-padrão, valores até 1,19 são considerados baixos; de 1,20 a 1,80 são intermediários; e acima de 1,80 são elevados.

Tabela 2 - Medidas dos construtos.

\begin{tabular}{l|c|c|c}
\hline \multicolumn{1}{c}{ Construto } & \multicolumn{1}{c}{ Alpha } & \multicolumn{1}{c}{ Média } & \multicolumn{1}{c}{ Desvio } \\
\hline Interesse pessoal na área & 0,810 & 4,49 & 1,39 \\
Importância percebida & 0,896 & 5,57 & 1,23 \\
Domínio de habilidades em nível teórico & 0,864 & 4,30 & 1,21 \\
Domínio de habilidades em nível prático & 0,843 & 4,20 & 1,27 \\
Dificuldade percebida & 0,799 & 4,01 & 1,33 \\
Autoconfiança & 0,835 & 4,35 & 1,30 \\
\hline
\end{tabular}

Fonte: Dados da pesquisa (2008).

De acordo com os resultados apresentados na Tabela 2, a média do construto interesse pessoal ficou em um nível intermediário, indicando que, na amostra selecionada, os estudantes apresentam um interesse apenas moderado pela área de Contabilidade.

Já em relação às dimensões associadas à atitude dos estudantes em relação à área, observa-se, inicialmente, que a importância percebida $(5,57)$ ficou em um nível elevado, indicando, a despeito de não haver um interesse muito pronunciado da parte dos estudantes, que reconhecem o valor que os conhecimentos das disciplinas de Contabilidade têm para sua atividade profissional.

Por outro lado, as demais dimensões de atitudes (domínio de habilidades, dificuldade percebida e autoconfiança) ficaram todas com médias de nível intermediário. A indicação é de que os estudantes de Administração sentem-se apenas moderadamente seguros quanto ao domínio dos fundamentos teóricos, dos métodos e das técnicas contábeis e também de que os estudantes não consideram as disciplinas de Contabilidade difíceis, que percebem uma dificuldade moderada; mas se sentem moderadamente autoconfiantes no assunto (provavelmente pela limitação da experiência prática vivenciada na área contábil para estudantes de Administração). 
Quanto aos desvios-padrão, os valores verificados na Tabela 2 (variando de 1,21, para 'domínio de habilidades em nível teórico', até 1,39, para 'interesse pessoal na área'), indicaram valores intermediários, sinalizando que há uma boa convergência nas opiniões dos estudantes quanto às opiniões e posições expressas nas médias apresentadas.

\subsection{Análise de regressão}

Como forma de analisar mais profundamente a relação entre os construtos, foi testada a influência do conjunto de construtos de atitudes sobre o interesse, a partir das variáveis agregadas. Para tanto, foi utilizada a técnica Análise de Regressão Múltipla, que, de acordo com Hair et al. (2005, p.136), possibilita analisar a relação entre uma variável dependente e várias variáveis independentes (chamadas de preditoras), viabilizando a avaliação da influência simultânea das variáveis preditoras sobre uma variável dependente previamente definida.

Para a análise de regressão múltipla, foram testados dois modelos: o primeiro, em que o construto domínio das habilidades foi testado nas duas dimensões que emergiram da análise fatorial (habilidades em nível teórico e habilidades em nível prático); e o segundo, no qual o domínio de habilidades foi utilizado como um construto de forma geral (gerado a partir da agregação das duas dimensões citadas).

Em cada caso, o construto associado a habilidades foi colocado como variável preditora, em conjunto com importância percebida, dificuldade percebida e autoconfiança; por outro lado, o construto interesse do estudante foi colocado como variável dependente. Os valores foram obtidos a partir do método enter, e cada modelo mostrou-se sempre consistente $\left(R^{2}=0,54\right.$ no segundo modelo e $R^{2}=0,52$ no primeiro). Os resultados dos coeficientes padronizados estão apresentados na Tabela 3.

Tabela 3 - Modelos de regressão múltipla

\begin{tabular}{|l|c|c|c|c|c|c|}
\hline \multirow{2}{*}{ Antecedentes do interesse } & \multicolumn{3}{|c|}{ Modelo 1 - hab. em dois níveis } & \multicolumn{3}{c|}{ Modelo 2 - hab. em geral } \\
\cline { 2 - 7 } & Valor $\boldsymbol{\beta}$ & Valor t & $\mathbf{p}$-value & Valor $\boldsymbol{\beta}$ & Valor t & $\mathbf{p}$-value \\
\hline Dom. de habilidades em nível prático & 0,091 & 1,095 & 0,275 & - & - & - \\
Domínio de habilidades (geral) & - & - & - & $-0,029$ & $-0,374$ & 0,709 \\
Importância percebida & 0,258 & 4,154 & 0,000 & 0,249 & 4,016 & 0,000 \\
Dificuldade percebida & 0,003 & 0,056 & 0,955 & 0,011 & 0,179 & 0,858 \\
Autoconfiança & 0,641 & 7,511 & 0,000 & 0,608 & 7,350 & 0,000 \\
\hline
\end{tabular}

Fonte: dados da pesquisa

Como é possível observar nos dois modelos, os construtos importância percebida e autoconfiança mostraram-se como antecedentes significativos do interesse em Contabilidade, ao passo que os construtos associados a domínio de habilidades e dificuldade 
percebida não alcançaram um nível de influência estatisticamente significativo. Ressalta-se ainda que, de acordo com os resultados, o construto com maior impacto sobre a formação do interesse do estudante de Administração pela área contábil é a autoconfiança $(\beta=0,641$ no primeiro modelo e $\beta=0,608$ no segundo), indicando-se um impacto menor da importância percebida ( $\beta=0,258$ no primeiro modelo e $\beta=0,249$ no segundo).

\subsection{Análise de agrupamentos}

Como forma de explorar ainda mais os dados coletados, as medidas dos construtos foram submetidas a uma análise de agrupamentos (análise de clusters). Assim, a partir do método $k$-means, foram extraídos três grupos, indicados na Tabela 4 pelos números 1,2 e 3, todos apresentados seguindo a ordem decrescente das médias encontradas para o construto interesse. Dessa forma, obtiveram-se as seguintes características:

- O grupo 1 foi formado por 35 respondentes (22,3\% do total) e caracterizou-se pelas médias elevadas em todos os construtos, com exceção somente para dificuldade percebida, que apresentou uma média baixa. Este grupo foi chamado de 'entusiasmados'.

- $\quad$ grupo 2 foi formado por 70 respondentes (44,6\% do total) e caracterizou-se pelas médias intermediárias em todos os construtos, com exceção apenas para 'importância, que recebeu uma média elevada. Este grupo foi chamado de 'moderados'.

- $\quad$ O grupo 3 foi formado por 52 respondentes (33,1\% do total) e caracterizouse pelas médias baixas em todos os construtos, com exceção apenas para importância percebida e dificuldade percebida, que recebera médias intermediárias. Este grupo foi chamado de 'não apreciadores'.

Um primeiro aspecto que merece destaque nesse resultado concerne às duas dimensões de domínio de habilidades. Observa-se que as médias, por grupo, nas duas dimensões são praticamente iguais, repetindo aqui o que foi observado no resultado geral (ver Tabela 2). A indicação é de que os grupos acreditam possuir, nessas duas dimensões de habilidades, o mesmo grau de competência.

Ainda de acordo com os resultados encontrados, merece destaque o construto importância percebida, que manteve uma média no mínimo intermediária no grupo dos 'não apreciadores'. Nos grupos dos 'entusiasmados' e 'moderados', as médias de importância já foram de um nível elevado. A indicação é de que os estudantes consideram a área importante para o curso, independente de manterem, ou não, interesse na mesma.

Outro destaque foi para o construto "Dificuldade percebida", que não teve média elevada em qualquer dos grupos. Observa-se que o grupo dos 'entusiasmados' apontou 
uma média muito baixa $(2,71)$, fato que reforça o sentido de entusiasmo deste grupo. Os dois demais grupos mantiveram um nível moderado de média, sinalizando que, em qualquer perspectiva de análise, os estudantes não consideram os conteúdos de Contabilidade como difíceis.

Tabela 4 - Resultados da análise de agrupamentos

\begin{tabular}{|l|c|c|c|c|}
\hline \multicolumn{1}{|c|}{ Construto } & Grupos & Número & Média & Desvio \\
\hline \multirow{3}{*}{ Interesse pessoal } & 1 & 35 & 5,81 & 0,96 \\
\cline { 2 - 5 } & 2 & 70 & 4,74 & 0,91 \\
\cline { 2 - 5 } & 3 & 52 & 3,26 & 1,17 \\
\hline \multirow{3}{*}{ Domínio de habilidades em nível teórico } & 1 & 35 & 5,54 & 0,80 \\
\cline { 2 - 5 } & 2 & 70 & 4,50 & 0,82 \\
\cline { 2 - 5 } & 3 & 52 & 3,20 & 0,90 \\
\hline \multirow{3}{*}{ Domínio de habilidades em nível prático } & 1 & 35 & 5,39 & 0,88 \\
\cline { 2 - 5 } & 2 & 70 & 4,39 & 0,98 \\
\cline { 2 - 5 } & 3 & 52 & 3,15 & 1,00 \\
\hline \multirow{3}{*}{ Importância percebida } & 1 & 35 & 6,33 & 1,03 \\
\cline { 2 - 5 } & 2 & 70 & 5,84 & 0,84 \\
\cline { 2 - 5 } & 3 & 52 & 4,68 & 1,30 \\
\hline \multirow{3}{*}{ Dificuldade percebida } & 1 & 35 & 2,71 & 1,00 \\
\hline \multirow{3}{*}{ Autoconfiança } & 2 & 70 & 4,42 & 1,17 \\
\cline { 2 - 5 } & 3 & 52 & 4,35 & 1,18 \\
\hline & 1 & 35 & 5,74 & 0,67 \\
\cline { 2 - 5 } & 2 & 70 & 4,64 & 0,82 \\
\cline { 2 - 5 } & 3 & 52 & 3,02 & 0,85 \\
\hline
\end{tabular}

Fonte: dados da pesquisa

\subsection{Outras considerações sobre os resultados}

$\mathrm{Na}$ amostra selecionada, foi possível apontar um interesse e uma atitude de grau apenas moderado, com discrepância mais evidente somente no construto importância percebida, no qual os estudantes atribuíram uma nota em um nível já elevado. Mesmo considerando a condição de uma amostra não probabilística, o que restringe as possibilidades de generalização, este resultado representa, na opinião dos autores, uma forte evidência de que a área de Contabilidade é algo de reconhecido valor na formação dos futuros profissionais de Administração. É relevante ressaltar que a amostra foi feita sem direcionamento por área de interesse prioritário dos estudantes, de modo que não se pode atribuir o viés que haveria se os estudantes pesquisados fossem somente aqueles interessados na área de finanças.

Os resultados da análise de regressão ilustram que, na amostra selecionada, o interesse dos estudantes tem condicionamento somente de importância percebida e de autoconfiança, 
não havendo indicativos de influência das dimensões de domínio de habilidade e de dificuldade percebida. O resultado é indicativo das prioridades que devem ser dadas por coordenadores de cursos ou professores da área contábil, se, efetivamente, querem ampliar o interesse dos estudantes: com efeito, devem ser realçados os pontos fortes das disciplinas, de modo a indicar a importância que ela possui, devendo ser criado um clima de confiança para que o estudante sinta-se autoconfiante.

Deve-se ter clareza dos resultados da regressão: no conjunto de todas as variáveis colocadas como antecedentes, somente duas mantêm uma predição estatisticamente significativa. As demais que não apresentam manifestação de influência não o fizeram especialmente em razão do procedimento convencional da técnica de análise de regressão, que exclui (ou torna sem efeito estatístico) as variáveis preditoras com correlação elevada com outras preditoras.

$\mathrm{Na}$ avaliação da correlação bivariada, exploratoriamente realizada, a variável representativa de interesse manteve correlação não nula com todas as outras e a variável dificuldade manteve correlação não nula e negativa com todas as demais, com exceção de importância, com a qual manteve correlação estatisticamente nula. Isso sugere, portanto, que as dimensões associadas ao domínio de habilidades na área e de dificuldade percebida são também relevantes, tendo seu efeito reduzido pela presença das duas demais variáveis no modelo de regressão. A indicação é, portanto, que todas essas dimensões devem ser pensadas pelos professores que, efetivamente, têm a preocupação de manter um interesse elevado por parte dos estudantes, devendo ser dada ênfase maior na autoconfiança (que provavelmente contribui para reduzir a percepção de dificuldade) e na importância percebida (que provavelmente motiva o aluno a desenvolver um maior domínio das habilidades).

Assim, os resultados dos grupos gerados indicam de maneira mais clara as fontes da variação existente no conjunto. Com efeito, temos, aproximadamente, um em cada cinco estudantes que é fortemente entusiasmado com a área contábil e este é ou será, provavelmente, mais inclinado para a área de finanças do curso. O grupo dos 'moderados', por outro lado, é o que representa melhor o conjunto de estudantes, ficando todos com média bem próxima da média geral.

Por fim, o grupo dos não apreciadores da Contabilidade é realmente avesso, sendo em boa medida crítico, inclusive quanto à importância da área para o curso. É relevante destacar nesse grupo sua dimensão, pois representam $33,1 \%$ do total de respondentes da amostra. A indicação é bem clara: um em cada três estudantes não tem muito interesse na área, não tem domínio de habilidades, não se sente autoconfiante e somente considera a área importante em um nível moderado. Veja-se, no entanto, que sua percepção de dificuldade não foi elevada, indicando aqui que tal posicionamento não advém de uma dificuldade mais pronunciada de compreender a área. A pesquisa aqui desenvolvida não tem como apontar, por outro lado, quais seriam as razões para tal posicionamento em um grupo tão 


\section{repec}

Francisco José da Costa, Thiago Alves Paiva, Jacqueline dos Anjos da Rocha e Roberto Rodrigues Ramos

expressivo de alunos. Uma maior exploração, a quem interesse, pode ser desenvolvida em estudos futuros.

\section{CONSIDERAÇÕES FINAIS}

O trabalho desenvolvido originou-se a partir de diversas leituras e avaliações de pesquisas sobre interesse disciplinar e temático de estudantes de Administração, bem como de diversos diálogos entre os autores. Os diversos questionamentos desenvolvidos formaram a base dos objetivos delineados e do trabalho de campo. Assim, o estudo teve a finalidade de avaliar como os estudantes de cursos de Bacharelado em Administração avaliam seu interesse pela área de Contabilidade presente nas grades curriculares dos cursos, além de avaliar aspectos associados às atitudes dos estudantes quanto à área, em termos de segurança quanto às habilidades da área, de importância, de dificuldade percebida e de autoconfiança.

Pelos resultados relatados, esses objetivos foram satisfatoriamente atingidos. Como principais implicações acadêmicas, acredita-se que este estudo poderá servir como referencial comparativo para análises de outras áreas presentes nos cursos de Administração (Economia, Direito, Ciências Humanas, entre outras), além de servir de base comparativa para outros estudos com objetivos semelhantes que podem ser realizados em outros contextos ou momentos.

Acredita-se ainda que este trabalho apresente implicações de natureza prática, podendo servir como um referencial para a ação de coordenadores de cursos e professores de Contabilidade em cursos de Administração, além de autores de materiais didáticos, que podem aproveitar as informações para melhor decidirem sobre argumentos e conteúdos a serem trabalhados nos cursos.

Como todos os estudos de natureza científica, diversas foram as restrições a que este trabalho foi submetido, desencadeando assim algumas limitações. Entende-se que cada uma das limitações desencadeia a sugestão de novos desenvolvimentos de pesquisa. Assim, são apresentadas a seguir algumas limitações e recomendações.

A primeira limitação consistiu na seleção dos aspectos associados ao interesse, tendose aqui mantido a limitação sobre os construtos presentes na escala de atitudes de Costa et al. (2008). Pelo que se observou nos resultados, os construtos somente conseguem explicar pouco mais de $50 \%$ da variação do interesse, havendo outros fatores não considerados no estudo e que podem ser muito importantes para análise. A literatura é rica em possibilidades de análises e recomenda-se que outros estudos procurem abordar esses outros aspectos.

As decisões sobre a amostragem, com um número pequeno de elementos em relação ao universo e com abordagem por conveniência, são fatores que também comprometem a possibilidade de generalização dos resultados, apesar de gerarem evidências significativas 
das relações testadas. Nesses termos, uma sugestão seria desenvolver amostragens probabilísticas e, se possível, desenvolver comparações de resultados.

\section{REFERÊNCIAS}

ANDRADE, R. O. B.; AMBONI , N. Gestão de cursos de Administração: metodologias e diretrizes curriculares: São Paulo: Prentice Hall, 2004.

BAGOZZI, R. P.; EDWARDS, J. R. A general approach for representing constructs in organizational research. Organizational Research Methods, v. 1, n. 1, p. 45-87, 1998.

CAMEY, J. P.; WILLIAMS, J. K. Selling principles: influencing principles of Marketing students' perceptions and attitudes toward Marketing as a discipline. Journal of Marketing Education, v. 26, n. 2, p. 154-160, aug. 2004.

COMISSÃO DE VALORES MOBILIÁRIOS (CMV). Deliberação CVM n. 29/86. Brasília: CVM, 1986.

COSTA, F. J.; ANDRADE, R. J. C; LIMA, M. C. Uma analise do interesse de estudantes de cursos de Administração pela área de produção e operações. In. Simpósio de Administração da Operação Logística e Operações Internacionais, 11, 2008, São Paulo. Anais eletrônicos... São Paulo: SIMPOI, 2008.

.; LOPES-JÚNIOR, E. P.; LEMOS, A. Q.; LÔBO, R. J. S. Atitudes dos estudantes de cursos de Administração quanto às disciplinas de métodos quantitativos: desenvolvimento de uma escala de mensuração. Texto para discussão, 6. Fortaleza: Eduece/CMAAd, 2008.

.; SOARES, A. A. C. Uma análise da formação científica em cursos de graduação em Administração: a perspectiva dos alunos. Revista de Gestão - REGE, v. 15, n.1, p. 47-60, 2008.

FERREIRA, R. J. Contabilidade Básica. 3 ed. Rio de Janeiro: Ferreira, 2007.

FRANCO, H. Contabilidade geral. 23. ed. São Paulo:Atlas, 1997.

HAIR, J. F.; ANDERSON, R. E.; TATHAM, R. L. BLACK, W. C. Análise multivariada de dados. 5. ed. Porto Alegre: Bookman, 2005.

HENDRIKSEN, E. S.; VAN BREDA, M. F. Teoria da Contabilidade. São Paulo: Atlas, 1999. 
IUDÍCIBUS, S. Teoria da Contabilidade. 9. ed. São Paulo: Atlas, 2009.

; MARION, J. C. Curso de Contabilidade para não contadores: para as áreas de administração, economia, direito e engenharia. 6 ed. São Paulo: Atlas, 2009.

MALHOTRA, N. K. Marketing research: an applied orientation. 3 ed. New Jersey: PrenticeHall, 1999.

MARION, J.C. Contabilidade empresarial. 14. ed. São Paulo: Atlas, 2009.

MARTINS, E. Contabilidade de custos. 9. ed. São Paulo: Atlas, 2003.

MATARAZZO, D. C. Análise Financeira de Balanços. 6. ed. São Paulo: Atlas, 2003.

MINISTÉRIO DA EDUCAÇÃO - MEC. Diretrizes curriculares nacionais dos Cursos de Graduação em Administração, bacharelado. Resolução No. 4, de 13 de julho de 2005. Disponível em: <http://portal.mec.gov.br>. Acessado em: 05 nov. 2008.

MENDES, I. G. Controladoria estratégica: sistemas de controles evoluem e ganham valor estratégico nas organizações. Revista Fae Business, n. 4, p. 51-54, dez. 2002.

NAZARIO, N. S.; MENDES, P. C. M.; AQUINO, D. R. B. Percepção dos Discentes quanto à Importância do Conhecimento em Contabilidade tributária em Instituições de Ensino Superior do Distrito Federal: um Estudo Empírico. In: Encontro anual da ANPAD, 30, 2006, Salvador. Anais... Salvador: ANPAD, 2006.

OLIVEIRA, L. M.; CHIEREGATO, R.; PEREZ JR., J. H.; GOMES, M. B. Manual de Contabilidade tributária. São Paulo: Atlas, 2003.

PAULO, E. Comparação da estrutura conceitual da contabilidade financeira. Dissertação (Mestrado) - Convênio Universidade de Brasília/Universidade Federal da Paraíba - Universidade Federal de Pernambuco/Universidade Federal do Rio Grande do Norte. João Pessoa - PB, 2002.

\section{SÁ, A. L. Teoria da Contabilidade. São Paulo: Atlas, 1998.}

SOUZA, Marcos Antonio; LISBOA, Lázaro Plácido, ROCHA, Welington. Práticas de Contabilidade Gerencial adotadas por subsidiárias brasileiras de empresas multinacionais. $\mathbf{R e}-$ vista Contabilidade e Finanças - USP, São Paulo, n.32, p.40-57, 2003. 


\section{APÊNDICE - VARIÁVEIS, MÉDIAS E DESVIOS-PADRÃO.}

\section{Interesse pessoal na área}

\begin{tabular}{l|l|l}
\hline Variáveis & Média & Desvio \\
\hline As disciplinas de Contabilidade são para mim muito interessantes. & 4,95 & 1,72 \\
Eu faria as disciplinas desta área, mesmo que não fossem obrigatórias. & 4,87 & 1,76 \\
Eu realmente gosto de cursar as disciplinas de Contabilidade. & 4,40 & 1,70 \\
Eu estudo Contabilidade para minha satisfação pessoal. & 3,73 & 1,79 \\
\hline
\end{tabular}

\section{Domínio de habilidades em nível teórico}

\begin{tabular}{|c|c|c|}
\hline Variáveis & Média & Desvio \\
\hline $\begin{array}{l}\text { Domino bem os conceitos básicos de Contabilidade (ativo, passivo, patrimônio } \\
\text { líquido, entre outros). }\end{array}$ & 4,60 & 1,49 \\
\hline Entendo as características e a estrutura das demonstrações contábeis. & 4,26 & 1,38 \\
\hline Compreendo bem o desenvolvimento de sistemas contábeis. & 3,93 & 1,45 \\
\hline Compreendo os resultados da análise de demonstrativos contábeis. & 4,42 & 1,43 \\
\hline
\end{tabular}

\section{Domínio de habilidades em nível prático}

\begin{tabular}{|c|c|c|}
\hline Variáveis & Média & Desvio \\
\hline Consigo usar a informação contábil no processo de gestão empresarial. & 4,25 & 1,43 \\
\hline Compreendo como se dá o fluxo das contas utilizadas pela Contabilidade. & 4,41 & 1,47 \\
\hline $\begin{array}{l}\text { Sou capaz de aplicar fundamentos contábeis nas decisões estratégicas das em- } \\
\text { presas. }\end{array}$ & 4,16 & 1,60 \\
\hline $\begin{array}{l}\text { Compreendo a aplicação das normas tributárias (impostos, taxas, contribuições) } \\
\text { nas atividades organizacionais. }\end{array}$ & 3,99 & 1,66 \\
\hline
\end{tabular}

\section{Importância percebida na área}

\begin{tabular}{l|c|c}
\hline Variáveis & Média & Desvio \\
\hline Eu considero necessário que todos os alunos do curso devem fazer as disciplinas & 5,70 & 1,60 \\
desta área. & 5,31 & 1,53 \\
O conhecimento da área é necessário para as demais disciplinas do curso. & 5,52 & 1,53 \\
O conhecimento da área é necessário para uma boa formação profissional. & 5,83 & 1,35 \\
As empresas necessitam de profissionais com conhecimento nesta área. & 5,74 & 1,49 \\
O que aprendo nas disciplinas desta área é importante para minha formação & & \\
profissional. & 5,30 & 1,63 \\
O conteúdo aprendido nas disciplinas de Contabilidade será útil no meu dia a dia. & 5 \\
\hline
\end{tabular}




\section{Dificuldade percebida na área}

\begin{tabular}{l|c|c}
\hline Variáveis & Média & Desvio \\
\hline As disciplinas de Contabilidade são muito complicadas. & 3,97 & 1,81 \\
As disciplinas desta área são mais difíceis que as demais disciplinas do curso. & 3,75 & 1,67 \\
Considero que as disciplinas de Contabilidade são difíceis. & 3,92 & 1,65 \\
O conteúdo das disciplinas desta área é muito complexo. & 4,43 & 1,61 \\
\hline
\end{tabular}

\section{Dificuldade percebida na área}

\begin{tabular}{l|c|c}
\hline Variáveis & Média & Desvio \\
\hline Sinto-me seguro quando faço avaliações de Contabilidade em sala. & 4,30 & 1,58 \\
As disciplinas de Contabilidade não me amedrontam. & 4,88 & 1,68 \\
Eu sou muito talentoso em Contabilidade. & 3,97 & 1,54 \\
As disciplinas de Contabilidade são fáceis para mim. & 4,24 & 1,56 \\
\hline
\end{tabular}

